\title{
Resenha: Bases Psicológicas e Sociológicas da Psicologia Social
}

\author{
Ana Raquel Rosas Torres ${ }^{1}$ \\ Universidade Católica de Goiás
}

\section{Book Review: Psychological and Sociological Bases of Social Psychology}

Os historiadores costumam afimar que a única maneira de entendermos o presente e planejarmos o futuro é conhecendo o passado. No entanto, conhecer o passado não é uma tarefa fácil, principalmente quando falamos da Psicologia e, em especial, da Psicologia Social. Entre as dificuldades envolvidas nessa tarefa podemos citar, por exemplo, aquelas ligadas à sua "paternidade". Dependendo da perspectiva adotada, essa paternidade pode ser atribuída a Émile Durkheim, a Wilhem Wundt, a Floyd Allport, só para citar as possiblidades mais conhecidas dos psicólogos. E, embora todos tenham falado da Psicologia Social, cada um falou à sua maneira. Assim, se pudéssemos definir essa disciplina em uma única palavra, talvez essa palavra fosse "diversidade". Diversidade teórica e metodológica. Diversidade geográfica. Diversidade filosófica. Diversas diversidades... Como, então, organizar essa história tão diversa?

Coube a José Luis Álvaro e a Alícia Garrido, da Universidade Complutense de Madrid, essa tarefa em seu livro "Psicologia Social: Perspectivas Psicológicas e Sociológicas". Tarefa que foi realizada com bastante elegância e clareza.

A proposta dos autores é discutir criticamente o desenvolvimento histórico dessa disciplina relacionando os seus principais desdobramentos teóricos com as concepções epistemológicas e metodológicas vigentes em cada momento dessa história. Além disso, os autores se propõem a articular o surgimento da Psicologia Social com as mudanças que ocorreram no seio da própria filosofia das ciências. Toda essa empreitada é realizada tendo em mente que "as teorias não surgem num vácuo histórico, mas são reflexo das circunstâncias e dos problemas que analisam e que procuram responder" (Álvaro \& Garrido, 2007, p. 11).

Sem dúvida, são objetivos ambiciosos que, para serem alcançados, os autores lançam mão de estratégias que podem ser consideradas, no mínimo, criativas. Assim, o livro está organizado em cinco capítulos, cobrindo desde meados do século XIX até a atualidade. Cada um dos capítulos inicia-se com uma ampla discussão acerca da concepção majoritária de ciência no período analisado. Em seguida, são analisados os principais marcos teóricos vigentes naquele período, sempre procurando ressaltar que as fundações da Psicologia Social estão na encruzilhada entre a Psicologia e a Sociologia. Os capítulos terminam sempre com a revisão metodológica envolvida no processo de amadurecimento da Psicologia Social. Aqui é importante ressaltar que no livro constam 41

1 Endereço: Av. Universitária, 1440, Setor Universitário, Goiânia, GO, Brasil 74605-010.E-mail: ar.torres@ucg.br resenhas biográficas que, além de narrarem fatos pitorescos da vida dos autores analisados, possuem suas fotos, o que ajuda a dar "uma cara" às teorias discutidas.

O primeiro capítulo apresenta os primórdios do pensamento psicossociológico e isso é feito de maneira, digamos, geográfica, uma vez que essa apresentação é organizada de acordo com os países de origem dos autores cujas idéias são discutidas. O segundo capítulo cobre o processo de independentização disciplinar da Psicologia Social, processo esse que começa com a Völkerpsychologie de Wilhem Wundt e vai até os desdobramentos do interacionismo simbólico de George Mead.

A consolidação da Psicologia Social, ocorrida nos anos 1930 e 1940, é discutida no terceiro capítulo e traz informações inéditas para o leitor brasileiro sobre os trabalhos de Frederic Bartlett e de Talcott Parsons. O quarto capítulo apresenta a evolução dessa disciplina até os anos 1970, ressaltando que essa evolução só foi possível graças às mudanças ocorridas no seio da filosofia da ciência 20 anos antes.

O quinto e último capítulo é, a meu ver, o mais denso e importante de todo o livro. Ele se inicia com uma discussão detalhada das mudanças profundas sobre a própria concepção de ciência no âmbito acadêmico e relaciona o amadurecimento teórico-metodológico da Psicologia Social com essas mudanças. Toda essa discussão é feita a partir de um ponto de vista que procura integrar tanto as concepções psicológicas como sociológicas do ser humano. Para nosso público, esse capítulo traz muitas informações inéditas, principalmente no que se refere às investigações realizadas na Universidade de Bristol, na Inglaterra, por Henri Tajfel e colegas, e que marcam o início da perspectiva das relações intergrupais. Em seguida, os autores apresentam a Teoria das Representações Sociais, de Serge Moscovici, esta já bem conhecida no Brasil. A influência das idéias de Jean Piaget na Psicologia Social é discutida a partir dos estudos desenvolvidos na Universidade de Genebra, na Suiça, pelo grupo liderado por Willem Doise. No entanto, as grandes surpresas do capítulo ainda estão por vir. A primeira refere-se à discussão das relações entre o pós-modernismo e a Psicologia Social realizada a partir de autores como Kenneth Gergen, Rom Harré e Michael Billig. A segunda é a explicitação das relações da Psicologia Social e da Sociologia por meio da discussão das idéias de Anthony Giddens, Norbert Elias e Pierre Bourdieu. A terceira é a discussão lúcida a respeito da polêmica que envolve os debates sobre as pesquisas qualitativas e quantitativas e enfatiza que a opção metológica do investigador deve ser feita imbricada à lapidação do objeto de estudo, pois, segundo os autores, "a escolha dos métodos e técnicas de investigação deve estar subordinada à natureza do objeto de estudo e não o 
contrário" (Álvaro \& Garrido, 2007, p. 479). Por outro lado, esse capítulo também apresenta algumas diferenças com a edição espanhola, lançada em 2003. Primeiro, os autores acrescentaram os trabalhos de Ajzen e Fishbein (1980; Fishbein \& Ajzen, 1975) sobre a Teoria da Ação Racional e sobre a Teoria da Ação Planejada. Além disso, os autores também incluíram uma importante discussão sobre as características da Psicologia Social que vem sendo desenvolvida na América Latina, ressaltando suas diversas vertentes. Nessa discussão, os autores também incluíram o debate sobre as contribuições de Ignácio Martin-Baró no desenvolvimento de uma Psicologia Social que tivesse, acima de tudo, um compromisso inabalável com a construção de sociedades mais justas sem, contudo, perder de vista a importância do rigor metodológico necessário para a consolidação desse campo de saber científico.

Sem sombra de dúvidas, esse é um livro denso que muito contribuirá para o entendimento do perfil atual da Psicologia
Social e que poderá servir como importante obra de referência para todos os interessados nas relações entre indivíduo e sociedade.

\section{Referências}

Ajzen, I. \& Fishbein, M. (1980). Understanding attitudes and predicting social behavior. Englewood Cliffs: Prentice-Hall.

Álvaro, J.L. \& Garrido, A. (2007). Psicologia Social: Perspectivas Psicológicas e Sociológicas. São Paulo: McGraw-Hill.

Fishbein, M. \& Ajzen, I. (1975). Belief, Attitude, Intention, and Behavior: An Introduction to Theory and Research. Reading: Addison-Wesley.

Recebido em 28.08.2005

Primeira decisão editorial em 19.06.2006

Versão final em 28.06.2006

Aceito em 13.03.2007

\section{REUNIÃO ANUAL DA SOCIEDADE DE PSICOLOGIA Ética e Política Científica na Psicologia}

Local: Florianópolis - SC

Período: 25 a 28 de outubro de 2007-07-10

\section{Realização:}

Sociedade Brasileira de Psicologia e

Universidade Federal de Santa Catarina

Informações e inscrição:

www.sbponline.org.br 